\title{
Cuando los espectadores sabemos más. El caso de Águila Roja
}

\author{
Dra. María Mercedes Vacas Gómez| mercedes.v.gomez@gmail.com \\ Universidad Politécnica Valencia
}

\author{
Palabras clave \\ Televisión, focalización espectatorial, \\ narrativa, entretenimiento, series \\ Sumario \\ 1. Introducción. 2. Metodología. 3. \\ Resultados 4. Discusión. 5. Conclusiones. \\ 6. Bibliografía.
}

\section{Resumen}

Águila Roja (2009 - 2016, TVE) ha sido una de las series más exitosas de los últimos años en España. La historia del héroe de capa y catana atrajo el interés de una audiencia numerosa que fue fiel a sus andanzas durante siete años. En este artículo se profundiza en uno de los aspectos de esta serie, cómo transmitió la información del argumento a los espectadores de forma poco común en la ficción audiovisual seriada. A través del planteamiento teórico se desarrolla el concepto de narrativa espectatorial aplicado al caso particular de Águila Roja, en la que el foco de información recae sobre la audiencia, que maneja mucha más información durante todo el relato que los propios personajes.

Partiendo de la observación como técnica esencial se ha realizado un amplio análisis de la organización de las tramas de esta serie. El objetivo es estudiar y ejemplificar como los datos claves en el desarrollo de la línea argumental principal se dan al espectador desde el comienzo del relato. De esta forma se descubren los giros principales de la historia pero con ellos se establece una relación empática entre audiencia y personajes que favorece la identificación y el enganche a la ficción.

\section{Cómo citar este texto:}

María Mercedes Vacas Gómez (2018): Cuando los espectadores sabemos más. El caso de Águila Roja, Miguel Hernández Communication Journal, 9 (1), pp. 71 a 99. Universidad Miguel Hernández, UMH (Elche-Alicante)

DOI: http://dx.doi.org/10.21134/mhci.v0i9.225 


\title{
When viewers do know more: the case study of Águila Roja
}

\author{
Dra. María Mercedes Vacas Gómez| mercedes.v.gomez@gmail.com \\ Universidad Politécnica Valencia
}

\author{
Keywords \\ Television, spectatorial targeting, narrative, \\ entertainment series \\ Summary \\ 1. Introduction. 2. Methodology. 3. Results \\ 4. Discussion. 5. Conclusions. 6. Bibliography.
}

\begin{abstract}
Águila Roja (2009 - 2016, TVE) has been one of the most successful Spanish TV series in recent years. The story of the hero with cape and katana attracted the interest of a large and massive audience, which was loyal to his adventures for seven years. In this paper, one of the main aspects of TV series is addressed, i.e. how to transmit the information to the audience in an uncommon way within the
\end{abstract} serial audiovisual fiction. From a theoretical approach, the concept of spectatorial narrative is developed and applied to the particular use case of Águila Roja. In this case, the main focus is on the audience, which is aware of much more information during the story than the characters themselves.

Taking observation as an essential technique, we have performed a wide and deep analysis of the organization of different storylines in this series. The objective is to study and give examples on the following aspect: the key information for the main storylines development are given to the audience from the very beginning of the story. In this way, the main changes of the story are revealed. However, an empathetic relationship between audience and characters is established. This favors both the identification and the addiction to that fiction.

\section{How to cite this text:}

María Mercedes Vacas Gómez (2018): When viewers do know more: the case study of Águila Roja. Miguel Hernández Communication Journal, 9 (1), pp. 71 to 99. Universidad Miguel Hernández, UMH (Elche-Alicante) DOI: http://dx.doi.org/10.21134/mhcj.v0i9.225 


\section{Introducción}

La creatividad narrativa en nuestros tiempos es una empresa difícil de conseguir. Lograr sorprender a unos espectadores cada vez más instruidos en lo que al arte de la ficción se refiere es el objetivo que persiguen todas las obras pero que se torna complicado en este siglo. Hacer que los personajes caminen por una delgada línea entre el bien y el mal es uno de los trucos más habituales para mantener la intriga en el espectador y sorprender a la audiencia. Lo que no es tan habitual, y menos en el sector audiovisual, es encontrarse con juegos sobre quién narra la historia y esto no es algo menor, ya que este es uno de los elementos narrativos más complejos y su dominio es de vital importancia para lograr esa sorpresa.

Águila Roja es una de las series más significativas de los últimos años en la industria televisiva española. Reconocida a nivel internacional, su éxito de audiencia y crítica reside, entre otros muchos aspectos, en su curiosa narrativa que mezcla géneros y técnicas de distintos formatos y la hacen muy atractiva para un público muy amplio. La serie sabe explotar muy bien las virtudes del formato y ha abierto el camino a una nueva forma de hacer dramedia, uno de los formatos más populares en España. Mezcla elementos de la dramedia, como por ejemplo las tramas familiares, con otros elementos propios del serial como los enredos, las intrigas, las situaciones melodramáticas, etc. que consiguen que en sus cuatro primeras temporadas la audiencia subiera exponencialmente hasta los 5.986.000 de espectadores, su mejor dato. La serie destaca por la complejidad de sus personajes, que se mueven en un continuo gris y unas tramas muy complejas. Pero una de sus cualidades más creativas e innovadoras de la es la relación que entabló con su público mediante la focalización espectatorial que aporta un plus sentimental muy atípico en las ficciones de larga duración. Este detalle tan original es el que ha impulsado este estudio en profundidad sobre su narrativa y sobre la forma de transmitir la información mediante distintas plataformas, explotando de esta forma todos los recursos que la nueva era de la información ha puesto a su disposición. 
En un principio las televisiones, en su breve historia, se alimentaron directamente de la industria cinematográfica, pero [...] la televisión ha llevado la ficción audiovisual al gran público y ha introducido una diversidad de estrategias narrativas que aún continúan alimentando el flujo creativo de la cocina televisiva (Francés y Llorca, 2012: 260).

Según Platón la mímesis crea la ilusión de que los hechos se cuentan por sí solos a través de los diálogos de los personajes, es la representación de la que habla Aristóteles en la que el narrador cede su palabra a los protagonistas. Por tanto, no es tan importante llegar a oír la voz del narrador sino conocer su posición, y la información que posee, en relación con los personajes. Ante un mismo acontecimiento podemos dar a la historia más o menos suspense, más o menos emoción, más o menos sorpresa a través del punto de vista desde el que se narra.

Como en la vida real, la información otorga un grado de superioridad que permite ver con mayor claridad las intrigas de una ficción. Como espectadores debemos tener en cuenta también la posición y el canal desde el que llega esa información para darle el grado de veracidad pertinente. Saber cuál es el foco para organizar la información que recibimos sobre la historia que nos están contando se torna fundamental en la organización de la historia porque debemos confiar o no en ella para reconstruir nosotros mismos el relato.

La problemática sobre el punto de vista narrativo se remonta a los primeros años del siglo XX debido a la inquietud que los teóricos de aquellos años tenían acerca de la objetividad de la novela moderna. El antecedente particular del que parte el concepto de focalización desarrollado por Gerard Genette en su famosa Tipología de tres términos (1972) parte de la obra de Jean Pouillon (1946) Temps et récit que años más tarde, en 1966, reinterpretó el teórico búlgaro - francés Tzvetan Todorov. Para Genette (1989: 49), estar en posesión de toda la información de una historia convierte al narrador, y por ende al espectador, en un ente omnisciente que domina a los personajes. Pero este no 
es siempre el caso, por lo que el autor establece tres niveles dependiendo de la cantidad de información que se posea en comparación con los personajes:

- Narrador > Personaje: El narrador sabe más que los personajes.

- Narrador = Personaje: El narrador no dice más de lo que saben los personajes.

- Narrador < Personaje: El narrador dice menos de lo que dicen los personajes.

En la industria audiovisual nos enfrentamos a una focalización cero de un meganarrador omnisciente que todo lo sabe pero que transmite de forma subjetiva las intenciones ocultas de cada personaje o la información que cada personaje por separado conoce de la historia. En la actualidad, muchos trabajos se han orientado hacia el estudio de este concepto de narrador omnisciente y su función dentro de la narrativa audiovisual. Por ejemplo, en 2001 Cuevas aplicaba el concepto de focalización a la representación de la subjetividad a través de los distintos planos, El autor se refiere en el artículo a otro concepto mucho más interesante para este estudio: la focalización cognitiva, que hace referencia a los estudios de Genette y Todorov sobre los diferentes grados de información que poseen los espectadores y los personajes.

A partir de informaciones fracturadas, que son el resultado de esa focalización cero, el espectador construye una realidad narrativa que acaba convirtiéndose en la historia. Sin embargo, ¿qué pasaría si ese meganarrador no aportara una realidad fraccionada al espectador para que este vaya uniendo piezas poco a poco? ¿Qué ocurriría si en cambio cediera cada secreto, cada mentira, cada giro de la historia al espectador para que este gestione toda la información como desee pero dejara en tinieblas a los personajes que se ven abocados a un destino ya escrito pero incierto para ellos?

Dar desde el comienzo este poder al espectador implica mantener un mismo punto focal durante toda la narración y deshacerse de las reservas de 
información que pueden causar las intrigas de las historias. Dar más o menos información al espectador es un elemento narrativo de gran importancia, porque su uso genera un juego entre el autor y la capacidad de intuir lo que pasará por parte del espectador. Bordwell asume en el apartado de tácticas de construcción del argumento de su libro La narración en el cine (1996) que "un argumento ideal proporciona información en la cantidad correcta que permite la construcción coherente y constante de la historia" (Bordwell, 1996: 54).

Si conocemos cada relación, cada alianza, cada traición de forma premeditada nos enfrentamos a una construcción narrativa que da la ventaja informativa al espectador desde el primer momento, y que ve el transcurrir de las vidas de los personajes sin poder intervenir en su destino aun teniendo la solución de todos los conflictos. Este meganarrador que todo lo sabe no corresponde a la focalización cero sino a otro tipo de focalización que Gaudreault y Jost (1995) se encargaron de definir a partir de dos nuevos conceptos esenciales en la industria audiovisual: la ocularización y la auricularización. El lenguaje audiovisual no implica únicamente colocar el foco de información a nivel de guion, como define Genette, sino que también implica ver y escuchar. Saber quién ve y quién escucha en cada momento para definir los canales de información de manera coherente.

Con estos dos nuevos conceptos en juego a los tres tipos de focalización propuestos por Genette, Jost suma uno nuevo: la focalización espectatorial. El autor entiende este concepto en términos de montaje, ya que ofrece un desequilibrio informativo entre espectadores y personajes ya que el espectador observa desde una posición privilegiada. "El espectador toma ventaja sobre el personaje únicamente por su posición, o más bien, por la que le atribuye la cámara" (Gaudreault y Jost, 1995: 152). Tal y como apunta Goméz Tarín en Saber y mirar: una propuesta de reformulación de los conceptos de focalización y ocularización en los discursos audiovisuales (2010) es difícil poder diferenciar entre una focalización externa y otra espectatorial ya que ambas parten de la objetividad de la imagen y lo que muestra o no. 
Cuando Jost establece las diferenciaciones para matizar el carácter de disparidad cognitiva entre espectador y personaje, considera habilitables una focalización externa y otra espectadora, pero el relato planteado de forma omnisciente ya abarca estas dos posibilidades; otra cosa es la disparidad cognitiva con el espectador (Gómez Tarín, 2010: 16).

Sin embargo, podemos extrapolar este mismo concepto a un nivel mucho más profundo, a un nivel de construcción narrativa que busca una nueva forma de contar historias en las que lo más importante para crear intriga y tensión no es el desconocimiento por parte de los espectadores sino que juega con la certeza de que el espectador es omnisciente y provoca reacciones emocionales en la audiencia. El espectador toma ventaja, sí, pero no puede hacer nada por sus queridos personajes que se encaminan hacia un destino que no pueden cambiar por la desinformación de la que son víctimas. El uso de la focalización espectatorial es común en las películas de suspense, pero que sea la base narrativa de una serie de larga duración es más inusual. Por esta razón suscita un especial interés cómo se han construido las tramas de Águila Roja (2009 - 2016, TVE) para mantener el interés del público durante siete años.

De forma resumida, este juego narrativo consiste en crear una expectativa en la audiencia que conoce de antemano la información y espera la reacción del personaje al enterarse o al enfrentarse a una situación comprometida. Esta anticipación a las emociones de los personajes por parte de los espectadores genera en estos últimos una mayor simpatía por el personaje en cuestión lo que le impulsa a seguir viendo la serie para descubrir cómo se resuelven estos enigmas. Este juego se logra gracias a la fragmentación y el manejo de la información de forma más innovadora. Se aleja de los planteamientos clásicos y habituales en la televisión y amplía sus historias a través de otras plataformas que se completan.

Es esencial para el éxito el cuidadoso manejo de estos conceptos. La fragmentación del discurso es un elemento definitorio de las series de televisión. La continuidad narrativa por medio de la fragmentación ha de 
encontrar una vía plausible que proporcione a la audiencia no solo un espacio único que de la sensación de que "de la mejor manera posible los diversos acontecimientos tienen lugar en la diégesis" (Prósper, 2013: 379), sino también un escenario narrativo que soporte la posible dilatación de la historia en el tiempo. En este sentido, el uso del concepto de focalización espectatorial ayuda a crear esa continuidad ya que el espectador piensa que gestiona la información principal, pero ésta en realidad queda relegada a un segundo plano durante la mayor parte de la narración por culpa de la fragmentación de la historia.

\section{Metodología}

La perspectiva metodológica parte de un profundo estudio teórico sobre los conceptos de transmisión de la información y de focalización. Estos aspectos teóricos se aplican a un análisis de la estructura narrativa y guiones de la serie de Águila Roja (2009 - 2016, TVE) con el objetivo de describir como hacen uso de la focalización espectatorial en la misma, como esta actúa en la identificación de la audiencia con los personajes y que técnicas más recurrentes utilizan para la consecución de dichos fines. A partir de este enfoque teórico se han estudiado distintos autores del siglo XX, como por ejemplo Genette, Jost, Vale o Lawson entre otros muchos que ayudan a asentar las bases de la focalización para posteriormente poder extrapolar sus conclusiones e investigaciones a las creaciones audiovisuales actuales.

Estos conceptos definidos durante el pasado siglo se adaptan ahora a las nuevas necesidades del mercado audiovisual y a las nuevas narrativas que han surgido en las últimas décadas gracias a las multiplataformas y, por tanto, a la posibilidad de desarrollar una historia desde distintos canales complementarios. La innovación nace de la reinvención y la reinterpretación de lo que ya está hecho, pero que en el siglo XXI tiene más posibilidades para ser transmitido de forma diferente, y juega con esa nueva coyuntura del mercado audiovisual. 
En consecuencia a las palabras de Aumont (1985) sobre el análisis del texto fílmico, partimos de un paradigma a medio camino entre el interpretativismo y la teoría crítica. El objetivo no es crear un conocimiento absoluto y objetivo sobre el concepto de focalización espectatorial como una forma innovadora de narrar, sino encontrar un significado y un punto de partida para futuras investigaciones ya que el análisis narrativo que se presenta en el siguiente apartado supone un complejo discurso que parten de factores subjetivos que dependen de la percepción de cada persona.

La visión del análisis fílmico de Aumont resulta especialmente interesante en lo relacionado a la definición del análisis y los instrumentos y técnicas empleadas. Lo esencial es mostrar una cierta flexibilidad en lo que respecta al análisis y a la aplicación teórica de los conceptos que se manejan en el caso particular de Águila Roja para poder llegar a unas conclusiones que validen la hipótesis planteada al inicio: el uso de la focalización espectatorial como técnica narrativa y no simplemente audiovisual. En tal caso nos enfrentaríamos a unos elementos narrativos que actuarían de manera extradiegética en la propia diégesis de la historia modificando por completo la enunciación del relato.

Como apunta Newcomb, (1993: 19) la investigación centrada en la producción dramática consta de dos líneas principales, por una parte, la observación y, por otra, las entrevistas con los profesionales. En este sentido, Casseti y Chio, al comienzo de su libro Cómo analizar un film (1998) apuntan que "del mismo modo que no existe una teoría unificada del cine, no se puede proporcionar ningún modelo universal de análisis de films". Por tanto, se ha optado por una metodología cualitativa, en lo que se refiere a métodos de investigación centrándonos en la observación como técnica esencial para el acercamiento al objeto de estudio. Está técnica junto con una sólida base teórica nos ayuda a formular sobre la narrativa usada en Águila Roja con el fin de ejemplificar el concepto de focalización espectatorial. 
Los resultados de esta investigación parten de un primer acercamiento al universo de Águila Roja recogido en la tesis doctoral La ficción televisiva española del siglo XXI a través de sus personajes (Vacas Gómez, 2017). En este artículo se extiende el análisis elaborado previamente prestando especial atención a cómo interactúan los bloques de tramas secundarias con el desarrollo de la trama principal de la serie: los orígenes de Gonzalo de Montalvo. El análisis se ha realizado tras la visualización completa de la serie y se ha escogido la quinta temporada en concreto porque en ella se empiezan a desvelar algunos de los secretos de la trama principal. Por esta razón es interesante observar como este hecho afecta a las tramas, al desarrollo de los personajes y a la fidelización de la audiencia.

La dilatación en el tiempo de las historias puede llevar al hartazgo por la larga espera. La pregunta que surge entonces es si, como creadores de historias, podemos sostener un relato en el que todo está contado. ¿Cómo puede ser aplicado este nuevo tipo de narración espectatorial en la creación audiovisual sin disminuir el interés de la audiencia? Y en lo que se refiere a los personajes y su construcción narrativa, ¿se crea un nuevo tipo de conflicto entre los personajes del que solo es consciente el espectador como observador omnisciente de toda la aventura? Y como consecuencia de esto, ¿es ese conflicto el foco que hace empatizar al espectador en mayor grado con los personajes?

Para poder dar respuesta a estas preguntas que conforman el grueso de la investigación desarrollada se han visualizado y analizado las tramas de Águila Roja prestando atención a la organización y desarrollo de las tramas por capítulos y temporadas y también a los personajes que las protagonizan. El análisis se ha realizado de la siguiente manera:

-En primer lugar se han visualizado los capítulos apuntando las tramas y personajes en los que se centran. 
-En segundo lugar se han colocado todas estas tramas en una gráfica para que sea más fácil visualmente entender el desarrollo y la relación entre las tramas a lo largo de los capítulos. También se han utilizado distintos colores para diferenciar los personajes o grupo de personajes que son protagonistas de cada una y como todas las tramas van incluyendo distintos personajes lo cual las complica y las alarga en el tiempo.

\section{Resultados}

La aplicación del concepto de focalización espectatorial a la construcción narrativa directamente y no tan solo a la fase de montaje crea una nueva forma de contar una historia en la que todo está desvelado de antemano. Por esta razón se ha de buscar caminos alternativos que atraigan al espectador hacia la historia que se cuenta además de usar la transmedia para que el flujo de información a través de otros canales sea constante y proporcionen al espectador una experiencia distinta al ver y disfrutar esa historia. En el caso concreto de Águila Roja notamos como este esquema narrativo creó un entramado complejo de tramas e interrelaciones entre sus personajes donde entró en juego un tercer factor: la conexión emocional y empática de los espectadores con las vidas de los personajes.

Al observar y analizar detenidamente como se interrelacionan los secretos y las tramas a lo largo de todos los capítulos notamos como este juego narrativo de la focalización aparece en momentos clave para mantener la atención de los espectadores y pierde importancia en favor de tramas secundarias que ayudan a alargar el relato. Pongamos como ejemplo la quinta temporada de la serie. El análisis minucioso de las tramas y los personajes que las protagonizan en esta temporada es especialmente interesante porque es en este momento de la historia cuando comenzamos a ver secretos revelados que antes se mantenían en la sombra. Cuando las tramas quedan solapadas por otras pero aún siguen desarrollándose, aunque no sea explícitamente durante el capítulo, aparecen en líneas intermitentes. En el análisis se han tenido en cuenta todas las tramas 
principales y secundarias más, es decir las que tienen más impacto en la serie porque afectan directamente al desarrollo de los personajes principales, que aparecen en los 18 capítulos de la quinta temporada de Águila Roja.

En la siguiente tabla, reflejo del análisis realizado, se observa cómo las tramas secundarias se van entrelazando, relegando a un segundo plano el argumento principal que sustenta la serie y que es el que el espectador conoce. Esa información tan valiosa que no poseen los personajes queda en un segundo plano y se recupera, de esta forma el control de la información. De esta manera, la serie vuelve a recurrir a las técnicas básicas de ocultación y revelación creando giros argumentales que los espectadores no se esperan.

Figura 1: Resumen, ordenación y relación de las tramas de la $5^{\mathrm{a}}$ temporada de Águila Roja: 


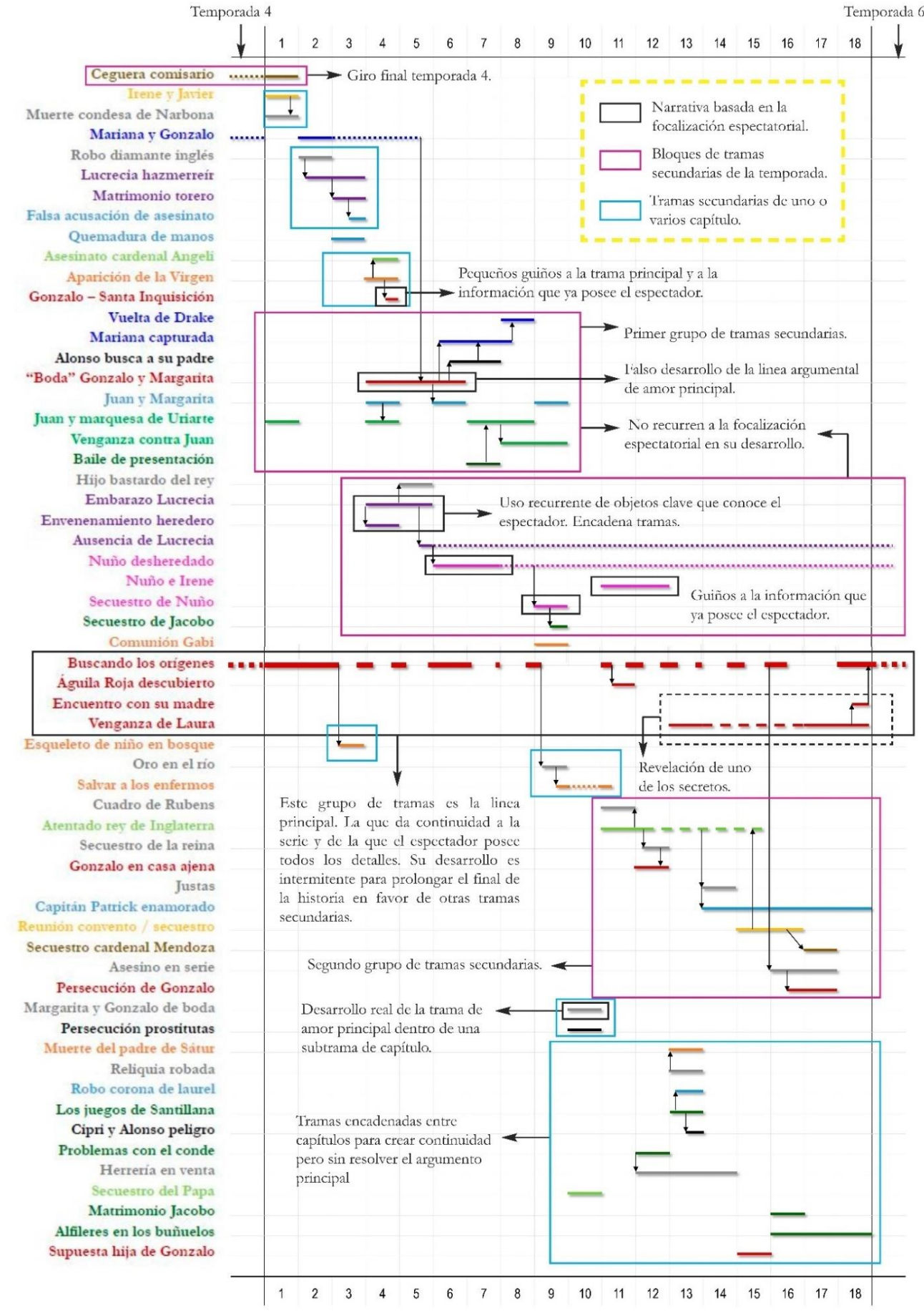

Fuente: Elaboración propia (septiembre, 2017). 
Las tramas secundarias modifican el centro de atención de los espectadores, dejando actuar en segundo plano esa información que tienen para crear esas reacciones emocionales, pero generando nuevas historias adyacentes de las que la audiencia ya no tiene el control. Esta expansión de la historia no se realiza únicamente durante el capítulo. En la tabla podemos apreciar como las tramas y subtramas secundarias se van mezclando haciendo referencias puntuales a la información transmitida del argumento principal, solo para no perder la curiosidad del espectador, en forma de pequeñas píldoras que parece nunca se acaban de resolver y mostrar en el mundo diegético de la historia. Sin embargo, al final de esta quinta temporada, uno de los grandes secretos (la madre de Gonzalo) es revelado al personaje justo antes de que esta muera a manos de su otro hijo que también desconoce el secreto.

\section{Discusión}

La frase "pero X personaje no lo sabe" es la máxima con la que juega Águila Roja para crear una tensión dramática en todos los capítulos de la serie. Este tipo de suspense se basa en los secretos que unos y otros guardan. Toda la narrativa de la serie está montada sobre la focalización espectatorial organizando el relato de forma que se produzcan constantes encuentros entre personajes con el fin de que estos produzcan reacciones empáticas en los espectadores y estas les animen a seguir viendo el desarrollo con el deseo de que en algún momento todos estos secretos sobre los que flotan las tramas secundarias sean desvelados. 
Figura 2. Esquema que guía la búsqueda de Gonzalo de Montalvo.

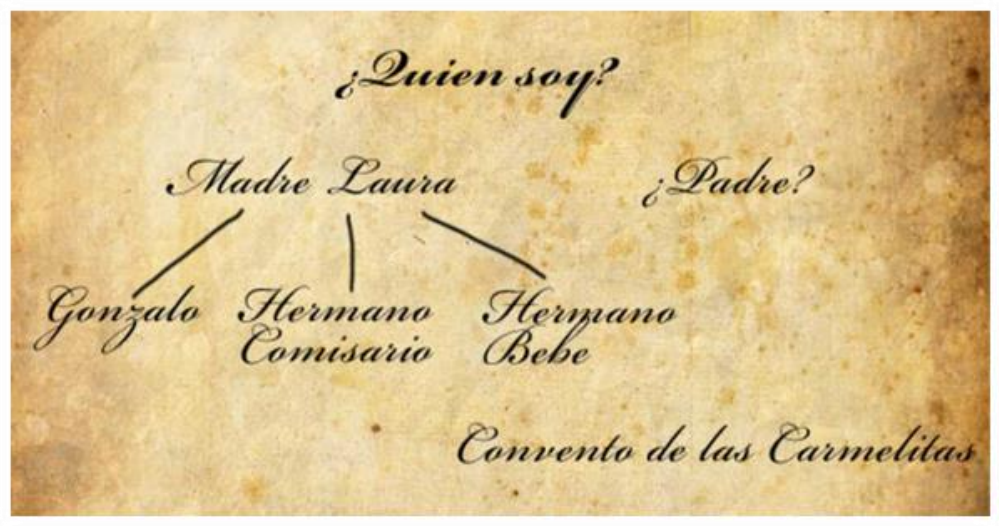

Fuente: página oficial de Águila Roja.

Bordwell asume en el apartado de tácticas de construcción del argumento de su libro La narración en el cine (1996) que "un argumento ideal proporciona información en la cantidad correcta que permite la construcción coherente y constante de la historia" (Bordwell, 1996: 54). Siguiendo las palabras del autor existen multitud de combinaciones de flujo de información, cada una con sus pros y sus contras, pero en este caso concreto el desequilibrio informativo a favor del espectador es una de las claves del éxito de la narrativa de esta ficción. El placer no consiste en averiguar al final quién era el asesino de Cristina o los orígenes de Gonzalo, el placer y tensión dramática nace del juego y las relaciones entre los personajes que en realidad no son conscientes del trasfondo de toda la historia.

La enunciación de un relato puede cambiar drásticamente la percepción que se tiene de este, el interés que despierta y en Águila Roja se lleva el nivel de enunciación mucho más lejos:

-Alonso no sabe que la persona que se esconde tras el héroe que idolatra es su padre al que desprecia por ser un hombre de libros y no de armas. 
-Hernán se casa por orden del cardenal con su sobrina Irene que en realidad es su hermana y en numerosas ocasiones están a punto de consumar su matrimonio, pero siempre son sorprendidos o interrumpidos.

-Alonso es salvado por una anciana mujer, pero no sabe que ella es su abuela.

-Gonzalo también se cruza y salva en muchas ocasiones a esta mujer pero no es hasta el final, cuando ella está muriendo, cuando se entera que es su verdadera madre a la que ha buscado durante tantos años.

-Lucrecia se pasa toda la serie intentando mejorar su estatus queriendo pasar a la historia y para ello se acuesta con el rey para procurar quedarse embarazada, pero no es consciente que Hernán, con el que mantiene una relación secreta es el verdadero y legítimo hijo mayor del rey.

-Nuño no sabe que su verdadero padre es Hernán y que su tía es por tanto Irene, con la que se acuesta y de la cual está enamorado.

Figura 3. Relaciones secretas entre los personajes. Fotogramas de los capítulos 5x07 y 6x01 de Águila Roja.
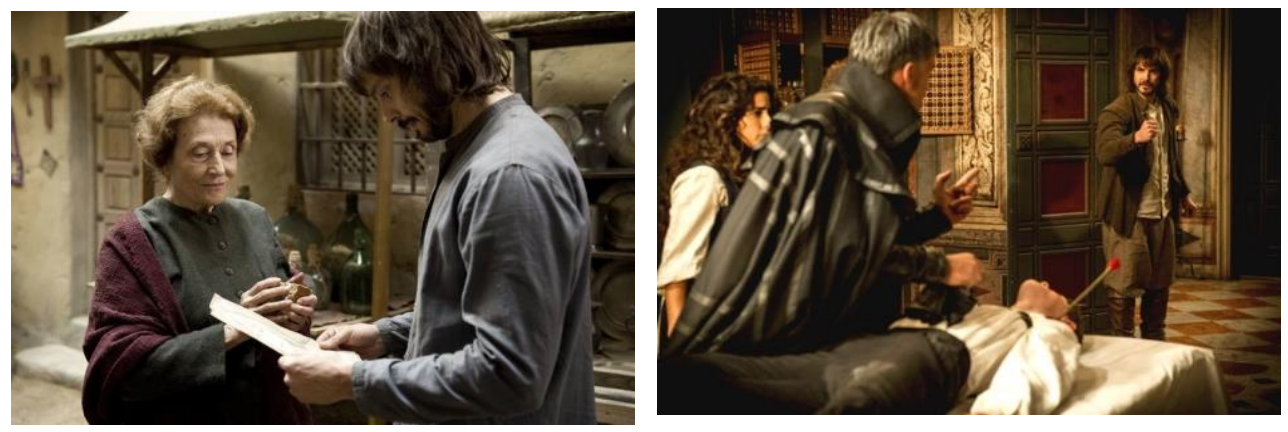

Fuente: página oficial de Águila Roja.

La serie no puede jugar con esos giros argumentales de la historia principal, cuando se descube una gran verdad sobre un personaje y ambos, espectadores y protagonistas, reaccionan al unísono. En cambio, Águila Roja juega de forma muy inteligente con la psicología de su público, con las emociones que desatan 
esas escenas de Hernán e Irene casi teniendo relaciones sexuales cuando son realmente hermanos o cuando Gonzalo ayuda a esa anciana vapuleada en medio de la plaza de la villa por robar un mendrugo de pan sin saber ninguno que son madre e hijo y que, además, ese mendrugo es para su nieto, Alonso, que está mal herido. Esta narrativa tan poco usada en las ficciones apela directamente a la identificación del espectador con el personaje de la serie desde la más profunda esencia del guion.

El efecto extradiegético del uso espectatorial de elementos significativamente diegéticos condiciona tanto la enunciación del relato como la implicación del espectador en el mismo. Este relato logra crear un proceso de identificación en la audiencia jugando con la psicología de los espectadores, rompiendo las convenciones sociales a su antojo refugiándose en la desinformación de los personajes.

La identificación es una de las armas más potentes que tiene la ficción a su servicio para crear historias aceptablemente convincentes que atrapen el interés de la audiencia. Es importante a la hora de plantear el guion de una ficción tener en cuenta que esta relación que nace entre el espectador y la obra es una "experiencia individual, psicológica, estética, en una palabra, subjetiva" (Amount, 1985: 227). Pero en el proceso de identificación no podemos tener en cuenta tan solo la parte psicológica. La relación emocional establecida y, por tanto, el deseo de seguir una historia, de saber más sobre un personaje dependen, a partes iguales, de esa psicología y de la estructura narrativa y el flujo de información que se proporciona al espectador.

Lo principal para lograr una identificación diegética es encontrar una conexión cultural con el relato que ayude al espectador a ponerse en la piel de un determinado personaje aunque no comparta sus motivaciones o sus acciones. En este sentido, Lawson dice: "identification is more than sympathy with that character; it is a "living in the character" (Lawson, 1949: 260). Ese efecto también depende del uso de los estereotipos como formas reconocibles para 
los espectadores que ayudan en este proceso. Conocer de antemano la intrahistoria de los personajes, lo que les une y ha separado y, además, tener ese conocimiento en exclusiva se ha revelado como una potente herramienta para crear esa identificación y colocar al espectador a la espera de que se desvelen esas intimidades mientras la historia juega con sus sentimientos y sufren por el cruel destino que les guía.

La vinculación emocional que se establece entre los personajes y los espectadores es crucial en el uso del concepto de focalización espectatorial aplicado a la narrativa ya que genera una sensación de complicidad y de angustia por el futuro incierto hacia el que se dirigen los personajes y que el espectador conoce a la perfección. Esta narrativa hace uso de la transmedia para fortalecer este vínculo y seguir facilitando datos sobre la historia a la audiencia por distintos canales que no corresponden a los capítulos de la misma. Acrecienta ese apetito por saber y conocer como reaccionaran cuando toda la verdad sea descubierta.

Este juego entre los personajes y el espectador también se establece con objetos que aparecen en la serie y tienen un significado oculto. Un ejemplo es la copa de madera que tiene Gonzalo guardada y que en verdad es el cáliz de cristo que custodiaba su madre y que hace enfermar al que lo bebe. Toda esa intrahistoria del objeto es conocida por los espectadores que ven como los personajes están a punto de beber o la dejan en cualquier sitio como si no tuviera ninguna importancia. Otro ejemplo es el mordedor que Lucrecia regala al Rey en la quinta temporada como obsequio para el futuro heredero, con la intención de envenenarle y dejar el camino libre para el bebe que ella espera y que es hijo ilegítimo del Felipe IV.

La focalización espectatorial crea en la audiencia una reacción emocional que conlleva una mayor implicación en la historia. Como público te gustaría decirle al personaje: “¡No, no bebas!”, "¡es tu madre!” o "¡no lo hagas, es tu hermana!". Apartarlos de situaciones moralmente poco aceptables que se 
suceden por culpa del desconocimiento y que parecen inevitables. Esto deja a la audiencia en un lugar poco deseable, lo saben todo pero no pueden hacer nada. Así que la historia sigue, cumpliéndose siempre esa máxima: "pero $\mathrm{X}$ personaje no lo sabe". Para darle fluidez a la trama algunos secretos van siendo revelados poco a poco pero esta tensión se mantiene hasta el último capítulo.

Hemos de tener en cuenta que "en cualquier relato se puede encontrar una estructura, pero eso no significa que haya sido creada como quien construye un mecano" (Tubau, 2011: 57). Las manipulaciones en la organización de la historia no son el único factor que mantiene la intriga. Resulta muy interesante observar también como el uso de la repetición de una serie de códigos también tiene un gran valor a la hora de crear una identificación y, por tanto, que la estructura narrativa espectatorial tenga éxito. El uso de las mismas estructuras a la hora de plantear los capítulos, el uso recurrente de situaciones que enfrentan a determinados personajes con esa intrahistoria de la que hablábamos o recurrir a códigos visuales de carácter universal generan en la audiencia familiaridad con la narrativa y un enganche que va pasando capítulo a capítulo y temporada a temporada.

Las revelaciones de los secretos se muestran entonces como los grandes giros de la historia que afectan de forma directa al personaje proporcionando un nuevo conflicto para la siguiente temporada, como es el caso del descubrimiento de quién es en realidad Laura de Montignac. Pero, como decíamos, la alusión a estos secretos también es una pieza clave de las tramas secundarias. Como se puede apreciar la línea argumental secundaria de la primera mitad de la temporada representada en la tabla superior tiene que ver con los personajes de la marquesa de Santillana, Nuño y Hernán. La marquesa huye de la villa porque está embarazada del Rey, este planteamiento que es secundario da pie a desarrollar la historia entre Hernán y Nuño. Hernán intenta proteger los intereses de su hijo intentando no desvelar que él es su verdadero padre ya que perdería el título de marqués definitivamente. 
Sin embargo, un mal manejo de los tiempos en la revelación de los secretos puede conllevar a un hartazgo por parte de los espectadores. A partir de la cuarta temporada la audiencia comenzó a descender a pesar de que es a partir de esta temporada cuando empiezan a desvelarse algunos de los secretos de la trama principal. La bajada paulatina de audiencia es debida, entre otras razones, al parón sufrido a mitad de la quinta temporada que mantuvo en suspense la serie y también a que el desarrollo de la trama principal se había frenado bruscamente en favor de las tramas secundarias autoconclusivas.

Figura 4: Resumen de las audiencias de Águila Roja

\begin{tabular}{|c|c|c|c|c|c|}
\hline Temporada & Capitulos & Estreno & Final & \multicolumn{2}{|c|}{ Audiencias } \\
\cline { 4 - 6 } & & & & Espectadores & Share $\%$ \\
\hline $\mathbf{1}$ & 13 & $19-2-2009$ & $22-5-2009$ & 4.637 .000 & $25,5 \%$ \\
\hline $\mathbf{2}$ & 13 & $7-1-2010$ & $8-4-2010$ & 5.609 .000 & $28,4 \%$ \\
\hline $\mathbf{3}$ & 13 & $23-9-2010$ & $10-10-2011$ & 5.642 .000 & $29,4 \%$ \\
\hline 4 & 12 & $17-10-2011$ & $23-1-2012$ & 5.986 .000 & $29,6 \%$ \\
\hline $\mathbf{5}$ & 18 & $6-5-2013$ & $21-11-2013$ & 4.469 .000 & $23,4 \%$ \\
\hline $\mathbf{6}$ & 13 & $11-9-2014$ & $4-12-2014$ & 3.983 .000 & $21 \%$ \\
\hline $\mathbf{7}$ & 8 & $29-5-2015$ & $17-6-2015$ & 2.462 .000 & $13,2 \%$ \\
\hline $\mathbf{8}$ & 13 & $10-9-2015$ & $10-12-2015$ & 2.320 .000 & $12,5 \%$ \\
\hline $\mathbf{9}$ & 13 & $14-6-2016$ & $27-10-2016$ & 2.492 .000 & $15,2 \%$ \\
\hline
\end{tabular}

Fuente: Anuarios de GECA (2009 - 2016). Elaboración propia (2017).

Después de que Gonzalo averiguara quién era su madre y que estaba relacionada con los templarios lo único que le faltaba era descubrir quién es su padre. Así la temporada 8 registró los datos de audiencia más bajos, con tan solo 2.320.000 de espectadores y un tímido $12,5 \%$ de share. La última temporada, momento en el cual se revelan todos los misterios mejoro un poco los últimos datos, llegando a los 2.492.000 de espectadores y un 15,2\% de share. Aun así, sus peores datos estaban por encima de la media anual de la 
cadena que ha ido descendiendo desde un 16,4\% en 2009 hasta un 9,8\% en 2015.

La información que maneja el espectador y esas relaciones diegéticas narradas desde la focalización espectatorial son las que mantiene en suspense el alma de los espectadores. Aun siendo Hernán el gran antagonista de Gonzalo desde la perspectiva del héroe, el espectador sabe que este no es más que una marioneta del Cardenal Mendoza. Se apiada de él porque conoce su sufrimiento y está al tanto del amor por su hijo Nuño. La focalización espectatorial consigue mostrarnos el verdadero interior de los personajes que al fin y al cabo son "la materia prima fundamental con la que el autor dramático se ve forzado a trabajar" (Egri, 2009: 65). Por tanto, podemos concluir que la relación y la evolución de los personajes es el atractivo real de la serie. Podemos conocer la historia pero también nos pueden sorprender sus reacciones.

Tanto para ampliar la información de la trama principal, como para contar nuevas historias Águila Roja puso en marcha un sistema de transmedia y multiplataforma que consiguió atraer la atención de un público más amplio hacia las historias de capa y espada protagonizadas por Gonzalo de Montalvo. Esta expansión narrativa puede considerarse en un primer momento multiplataforma, ya que su expansión se realiza a través de distintas pantallas o soportes. Pero la experiencia multimedia de la serie llevó la inmersión del público más allá. La conjunción de la pasividad del espectador que solamente ve la serie, que asisten a la base narrativa de la serie, y la suma de otras plataformas que permiten una ampliación de la información base y el feedback. directo logró un mayor nivel de inmersión de los espectadores en la narrativa y consolidó el fenómeno fan creado alrededor de la serie.

La implicación de los espectadores en el desarrollo de las historias es un fenómeno muy en boga desde comienzos del siglo XXI que se ha visto favorecido por el avance de las tecnologías y las redes sociales y foros donde 
los espectadores pueden opinar y compartir sus teorías sobre el futuro de los personajes. Estas "nuevas narrativas” rompen con la linealidad y pasividad del espectador, aunque es necesario señalar que la serie no busca líneas argumentales alternativas, es decir, que el espectador se conforme su propio relato, sino que ofrece distintos contenidos autónomos pero relacionados entre sí por la temática o los personajes. Este flujo de información acentúa la focalización espectatorial del relato ya que proporciona nuevas informaciones que pueden ser consumidas o no por los espectadores, pero no influye en la comprensión final de la narración.

Como espectador puedes elegir ver la serie en televisión o en su web en el momento que desee, puedes leer los libros o jugar al videojuego, participar en las redes sociales o ver la película, pero todo esto puede ser consumido independientemente, no necesitas la película para entender la serie o el videojuego o el libro para poder continuar con una historia lógica que no obliga al consumo de todos estos productos, si no que invita a sus fans a hacerlo y disfrutarlo, lo que además genera mucha más rentabilidad del producto.

Cada medio hace lo que se le da mejor. Una historia puede ser introducida a través de una película, expandida a través de televisión, novelas, cómics y su mundo puede ser explorado y experimentado a través de un videojuego. Cada producto de la franquicia debe tener suficiente auto contenido para posibilitar su consumo autónomo (Jenkins, 2008: 101).

Quizás, en el caso concreto de Águila Roja, podríamos hablar de una transmedia "accidental" pensada para sacar un mayor rendimiento económico la historia de este particular héroe español. Lo cierto es que con el tiempo todos los aportes que el núcleo de la narración, la serie de televisión, ha obtenido de sus productos derivados es muy importante, sobre todo en lo que se refiere a esa focalización espectatorial que la define y da el poder absoluto al espectador que maneja desde el principio toda la información que atormenta a 
los personajes. La accesibilidad e interactividad de los espectadores con Águila Roja es una pieza clave que acrecienta la fidelización, participación y la creación del fenómeno fan en torno a esta producción.

El afán por vivir de distintas formas una historia, empaparse hasta ser prácticamente uno más en la ficción, es una de las grandes ventajas que el uso de la transmedia da a esta serie. La participación reinventa el consumo y la interpretación de la historia, que se llega a asumir como algo más cercano y propio. No importa el medio, ese deseo va evolucionando, renovándose con el avance de la sociedad. Cambia y se adapta aun pública cada vez más experimentado y exigente que busca nuevas formas de disfrute. Ese es el poder de la narrativa, de la imaginación y del deseo de conocer que es innato al ser humano.

Los primeros hombres solo conocían sus propias vidas [...] Gradualmente, esta visión se fue ampliando: pueblos que tenían distintas experiencias vitales empezaron a encontrarse. Deseosos de información sobre los otros, comenzaron a contar relatos [...] El deseo de vivir otra vida, o de superar los límites de la propia, creció en él (Vale, 1982: 12).

\section{Conclusiones}

Una vez realizado este profundo análisis sobre la organización narrativa de la serie y sobre la forma en la que transmite la información, es decir, alimentando la atención del espectador sin necesidad de avanzar significativamente en la línea argumental principal de la serie, podemos concluir que Águila Roja se ha convertido en uno de los grandes referentes de la ficción audiovisual seriada en España. La investigación que se desarrolla en este artículo cobra un verdadero sentido en el apartado de las conclusiones, al revelarse como se aplican y amplían los conceptos propuestos el pasado siglo en una narrativa larga sin un final cerrado, como la de las series de televisión. A todo ello se 
suma, por supuesto, las nuevas plataformas y todos los beneficios que aporta ampliar y distribuir una historia mediante distintos canales.

Del análisis podemos concluir que esta atípica narrativa que explota la focalización espectatorial en su línea argumental principal ha de ir acompañada de otras tramas que sigan un patrón narrativo más común para que el efecto sorpresa se mantenga y la focalización espectatorial no pierda fuerza a lo largo de las temporadas. Esta conjunción de tramas y técnicas entretejen una maraña de historias que se complican y se alargan, pausándose su desarrollo capítulo tras capítulo, y consiguiendo así mantener en vilo la atención del espectador. El uso de la focalización espectatorial no es más que un recurso que aporta cierto grado de originalidad al planteamiento de la serie. El aprovechamiento que hacen de la multiplataforma para transmitir y extender la historia también fue novedoso para la industria española, acostumbrada a una distribución más tradicional.

El conflicto interior que se crea en los espectadores al ver la ficción, provocado por la gran información que tienen gracias a la focalización espectatorial, entra en relación directa con la empatía e identificación con los personajes. Por unos instantes sus vidas consiguen fundirse con la de la audiencia y la percepción de veracidad en la ficción aumenta a pesar de que los hechos queden muy alejados de la realidad de los espectadores. La perspectiva del espectador nunca acaba materializándose en la diégesis narrativa, pero de ella depende el éxito de la misma. Al lograr que el espectador sienta y padezca con el personaje también se consigue una fidelización de la audiencia que perdura más en el tiempo. Proporcionar toda la información esencial del argumento principal consigue vender una historia que se desarrolla solo en insertos camuflados dentro de tramas secundarias que prolongan la vida de la serie.

Alargar de esta forma una historia que podría contarse en mucho menos tiempo pone en peligro la supervivencia y originalidad del propio relato. Como 
hemos visto en el apartado de discusión de los resultados del análisis la audiencia fue perdiendo poco a poco el interés en la historia de Gonzalo de Montalvo y del resto de los habitantes de la Villa porque la historia principal quedaba relegada a un segundo plano. De esta forma el poder de identificación de la focalización espectatorial queda diluido. Aun así, los espectadores nunca bajaron de los millones. Una fiel audiencia que aumento al final para disfrutar de la revelación final de la última temporada. Tras siete años, fueron los personajes los que mantuvieron la llama del éxito de Águila Roja.

Normalmente entendemos el cine como un medio más personal, de autor. En realidad, el cine también se ajusta a criterios comerciales y necesidades de rentabilidad económica y no por ello se ha de considerar menos artístico. Es posible que en el medio televisivo el horizonte de la rentabilidad económica dificulte que se puedan llagar a realizar producciones más atrevidas tanto en el fondo como en la forma. El miedo al fracaso de las cadenas, los productores ejecutivos, los anunciantes, los inversores, etc. son filtros que habitualmente no favorecen la calidad o desarrollo de producciones más originales. Pero aun así, moviéndonos dentro de una rentabilidad comercial, podemos encontrar pequeños destellos de creatividad, de narrativas que reinventan los conceptos y los explotan en su beneficio.

Es cierto que aún queda un largo camino por andar, pero solo hay que seguir caminando. Un amplio universo que explorar que se expande, cada día más, gracias a las nuevas tecnologías y las redes sociales que son capaces de reinventar narrativas que antes solo eran pura teoría. La interacción es prácticamente inmediata y eso influye directamente en la forma de contar, de transmitir historias. Las historias acaban hablando de personas, de sus sentimientos y emociones, más que de acontecimientos estériles que es el objetivo que ayuda a poder extender un universo ficcional a múltiples plataformas. Al fin y al cabo esa es uno de los grandes pilares de la humanidad, lo que ha movido a civilizaciones a lo largo de siglos y milenios. 


\section{Bibliografía}

Águila Roja: Página web oficial (Consultado el 3 de septiembre de 2017) Disponible en: http://www.rtve.es/television/aguila-roja/

Aumont, Jacques (1985). Estética del Cine. Buenos Aires: Paidos.

Bordwell, David (1985). Narration in the Fiction Film. Madison, Wiscosin: The University of Wiscosin Press.

Bordwell, David y Thompson, Kristin (1995). El arte cinematográfico: Una introducción. Barcelona: Paidos comunicación 68 cine.

Bourdieu, Pierre (1997). Razones prácticas. Sobre la teoría de la acción. Barcelona: Anagrama.

Casetti, Francesco y Di Chio, Federico (1998). Como analizar un film. Barcelona: Paidos.

Chatman, Seymour (2013). Historia y discurso. La estructura narrativa en la novela y en el cine. Madrid: RBA Editores

Cook, David A. (2004). A history of narrative film. New York: W.W.Norton.

Ducrot, Oswald y Todorov, Tzvetan(1995). Diccionario enciclopédico de las ciencias del lenguaje. México: Siglo XXI.

Cuevas, E. (2001). Focalización en los relatos audiovisuales. Trípodos, n. 11, 2001, pp. $123-136$ 
Egri, Lajos (2009): El arte de la escritura dramática para la interpretación creativa de las motivaciones bumanas. México: Centro de estudios Cinematográficos. Universidad Nacional Autónoma de México.

Francés, Miquel y Llorca, Germán (2012). La ficción audiovisual en España. Relatos, tendencias y sinergias productivas. Barcelona: Gedisa.

Gaudreault, André y Jost, François (1995). El relato cinematográfico. Cine y Narratología. Barcelona: Paidós.

GECA (2009 - 2016). Anuario de la televisión. Madrid: GECA.

Genette, Gérard (1989). Figuras III. Barcelona: Editorial Lumen.

Gómez Tarín, F. J. (2010). Saber y mirar: una propuesta de reformulación de los conceptos de focalización y ocularización en los discursos audiovisuales. http:/ /hdl.handle.net/10234/30111

Jenkins, H. (2008). Cultura de la convergencia. Barcelona: Paidós.

Lawson, John Howard (1949). Teory and technique of playwriting. New York: G.P. Putnam’s Sons.

Pouillon, Jean (1946). Temps et récit. Paris: Gallimard.

Propp, Vladimir (1977). Morfología del cuento. Madrid: Fundamentos.

Prósper Ribes, José (1991). El punto de vista en la narrativa cinematográfica. València: Fundación Universitaria San Pablo Ceu. 
Prósper Ribes, Josep (2013). El sistema de continuidad: montaje y causalidad. Historia y Comunicación Social. Vol. 18 Extra 1. Págs. 377-386.

Newcomb, H. M. (1993). La Creación del drama televisivo. En: Jensen, L.B. y Jankowski, N.W. (eds.) Metodologías cualitativas de investigación en comunicación de masas. Barcelona: Bosch Casa Editorial. Págs. 117-133.

Sánchez Escalonilla, Antonio (2002). Guion de aventura y forja del béroe. Barcelona: Ariel.

Tubau, Daniel (2011). El guion del siglo 21: el futuro de la narrativa en el mundo digital. Barcelona: Alba Editorial.

Vacas Gómez, María Mercedes (2017). La ficción televisiva española del siglo XXI a través de sus personajes (Tesis doctoral). Universitat Politècnica de València. València, España.

Vale, Eugene (1989). Técnicas del guion para cine y televisión. Barcelona: Gedisa. 


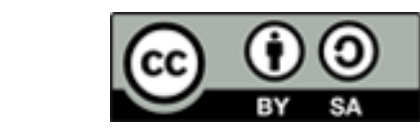

Licencia Creative Commons

Miguel Hernández Communication Journal

mhjournal.org

\section{Cómo citar este texto:}

María Mercedes Vacas Gómez (2018): Cuando los espectadores sabemos más. El caso de Águila Roja, Miguel Hernández. Communication Journal, 9 (1), pp. 71 a 99. Universidad Miguel Hernández, UMH (Elche-Alicante).

DOI: http://dx.doi.org/10.21134/mhcj.v0i9.225 